\title{
V. Remarkable property of mica
}

\section{P. Riess}

To cite this article: P. Riess (1846) V. Remarkable property of mica, Philosophical Magazine Series 3, 29:191, 25-26, DOI: 10.1080/14786444608562592

To link to this article: http://dx.doi.org/10.1080/14786444608562592

曲 Published online: 30 Apr 2009.

Submit your article to this journal $2 \pi$

Џ Article views: 4

Q View related articles $₫$ 


\section{[ 25 ] $]$ \\ V. Remarkable Property of Mica. By P. Rress*.}

A PIECE of clean mica becomes covered like other subA stances with a vast number of small drops of water at very small distances from each other, when it is breathed upon or held over steaming water. The layer of bubbles impairs the reflecting properties of the mica, and renders objects placed beneath it imperfectly visible; if by means of a sharp knife a very thin leaf be pealed off the mica, and thus a new surface given to it, and it then be again exposed to the aqueous vapours, the fresh surface remains perfectly transparent whilst the surrounding parts become dim as before. This curious fact is not accounted for by supposing no aqueous vapour to be condensed upon the fresh surface, for a distinct play of colours may be observed upon that part, showing it to be covered with a continuous thin layer of water. A drop of water, which remains in a globule upon an old surface of mica, immediately spreads out and moistens the whole extent of a fresh surface.

From its extreme purity, therefore, the fresh mica surface exerts so strong an affinity for aqueous vapour as to condense it in a continuous film, whereas, if it has been exposed for some time to the air, it can only condense the vapour in separate little globules. This may be distinctly seen under the microscope.

A fresh mica surface shows this property not only in an atmosphere nearly saturated with aqueous vapour, as is produced by an exhalation, but likewise in common air when far removed from a saturated state. It is well known that mica is one of the best non-conductors of electricity; a piece was chosen which did not in the least affect a charged electrometer during the space of a minute; on pealing off' a thin layer, the fresh surface discharged the electrometer in a few seconds, the old surface still remaining a non-conductor. That the power of conducting was due to a continuous layer of water, and could be removed by its evaporation, was proved by the following experiments.

A fresh mica surface placed in a box, the bottom of which was covered with chloride of calcium, could not, after a minute or two, be found to conduct electricity; it became however a conductor on the removal of the drying material and the renewal of the air in the box. Whilst heated, a similar leaf of mica did not conduct, but regained that power during cooling.

* Translated from Poggendorff's Annalen, No. 3, 1846, and communicated by Dr. E. Ronalds. 
The two metallic caps of a high insulated glass cylinder were connected by a freshly split leaf of mica in the interior of the cylinder: either cap discharged an electrometer on touching the other with the hand. When however the air was rarefied in the cylinder to two lines barometrical pressure, the electrometer was not discharged, for then the leaf of mica insulated completely. The insulation lasted for twenty-two hours, when on admitting a small quantity of air insulation was again destroyed, and the mica conducted as well as before.

Exposed to the air, mica retains this property but a short time. In a few hours parts of the fresh surface become dim when breathed on; in a day or two the whole surface, and the mica then insulates to a considerable extent.

The property of not becoming dim when breathed on is common to the scaly varieties of gypsum, and probably to other minerals. Calcareous spar possesses the property in a very slight degree, and loses it in a few minutes.

VI. On Quaternions; or on a Nero System of Imaginaries in Algebra. By Sir William Rowan Hamilton, LL.D., V.P.R.I.A., F.R.A.S., Corresponding Member of the Institute of France, Member of several other Scientific Societies in these and in Foreign Countries, Andrewes' Professor of Astronomy in the University of Dublin, and Royal Astronomer of Ireland.

[Continued from vol. xxvi. p. 224.]

18. THE separation of the real and imaginary parts of a quaternion is an operation of such frequent occurrence, and may be regarded as being so fundamental in this theory, that it is convenient to introduce symbols which shall denote concisely the two separate results of this operation. 'The algebraically real part may receive, according to the question in which it occurs, all values contained on the one scale of progression of number from negative to positive infinity; we shall call it therefore the scalar part, or simply the scalar of the quaternion, and shall form its symbol by prefixing, to the symbol of the quaternion, the characteristic Scal., or simply $\mathbf{S}$., where no confusion seems likely to arise from using this last abbreviation. On the other hand, the algebraically imaginary part, being geometrically constructed by a straight line, or radius vector, which has, in general, for each determined quaternion, a determined length and determined direction in space, may be called the vector part, or 